\title{
Adult onset of ganglioneuroblastoma of the adrenal gland: case report and review of the literature
}

\author{
Elena Bolzacchini*, Barbara Martinelli and Graziella Pinotti
}

\begin{abstract}
Ganglioneuroblastoma (GBN) is a malignant neoplasm of the autonomic nervous system. Adult onset of ganglioneuroblastoma is extremely rare. Only 16 cases have been reported in English literature, to date. Surgery represents the first-line therapy for the treatment of ganglioneuroblastoma. Radiation therapy is indicated in patients with localized unresectable disease. Chemotherapy is reserved for metastatic disease.

We present the case of a 63-year-old man affected by ganglioneuroblastoma of the adrenal gland. The diagnosis was made incidentally. The tumor, measuring $5 \times 3 \mathrm{~cm}$, was successfully surgically removed.
\end{abstract}

Keywords: Adrenal; Ganglioneuroblastoma; Adult onset

\section{Background}

Ganglioneuroblastoma (GBN) is a malignant neoplasm of the autonomic nervous system; it originates from primitive neuroectodermal cells of the neural crest that migrate during embryonic life giving rise to the sympathetic ganglia and the adrenal medulla. Ganglioneuroblastoma represents a subgroup of neuroblastoma tumors with a prominent, mature ganglion cell differentiation, usually located in the adrenal gland (the most frequent site) but also in the posterior mediastinum, the retroperitoneum, and the brain [1]. Adult onset is extremely rare. Only 16 cases of adrenal ganglioneuroblastoma of the adult are reported in English literature.

\section{Case presentation}

In November 2013, a 63-year-old Caucasian man underwent a CT scan for recurrent renal stones. A mass of the left adrenal gland measuring $5 \times 3 \mathrm{~cm}$ was incidentally found. The mass was irregular and hypodense and had inhomogeneous contrast uptake, especially in the arterial phase. Magnetic resonance imaging (MRI) confirmed the mass: the signal was highly inhomogeneous and the central area was partially fluid (see Fig. 1a, b). The radiologist's report excluded the diagnosis of adenoma but could not define the lesion.

The patient was in good clinical condition and asymptomatic. The complete physical examination was negative. Blood pressure and pulse were normal. Results of the complete blood count, plasma levels of electrolytes, tests of coagulation, kidney and liver function, and urinalysis were normal. For the history of nephrolithiasis, phosphocalcic profile was analyzed and primary hyperparathyroidism as a cause of kidney stones was excluded. Testing for adrenal gland function were all normal: in particular, urinary metanephrines and urinary free cortisol were normal, DHEAS = $1.7 \mathrm{mcg}$ (normal range: $0.2-3.3$ ), $17-\mathrm{OH}-\mathrm{Pg}=1.1 \mathrm{ng} / \mathrm{ml}$ (normal range: $0.4-3.3$ ), aldosterone $=291 \mathrm{pg} / \mathrm{ml}$ (normal range: $70-300 \mathrm{pg} / \mathrm{ml}$ ), renin $=13.2 \mathrm{MCU} / \mathrm{ml}$ (normal range: 7-76), aldosterone-renin ratio $=2.2$ (normal range $<3.4)$. All the tests were made in order to rule out the possibility of a functioning lesion. In particular, blood tests excluded hypercortisolism, so the patient could undergo surgery without risks.

A radical adrenalectomy with complete excision of the lesion was performed. The surgery was radical and without postoperative complication.

\footnotetext{
* Correspondence: elena.bolzacchin@hotmail.it

U.O Oncologia Medica, Azienda ospedaliero-universitaria Ospedale di Circolo e Fondazione Macchi, Viale Borri, 57, 21100 Varese, Italy
} 

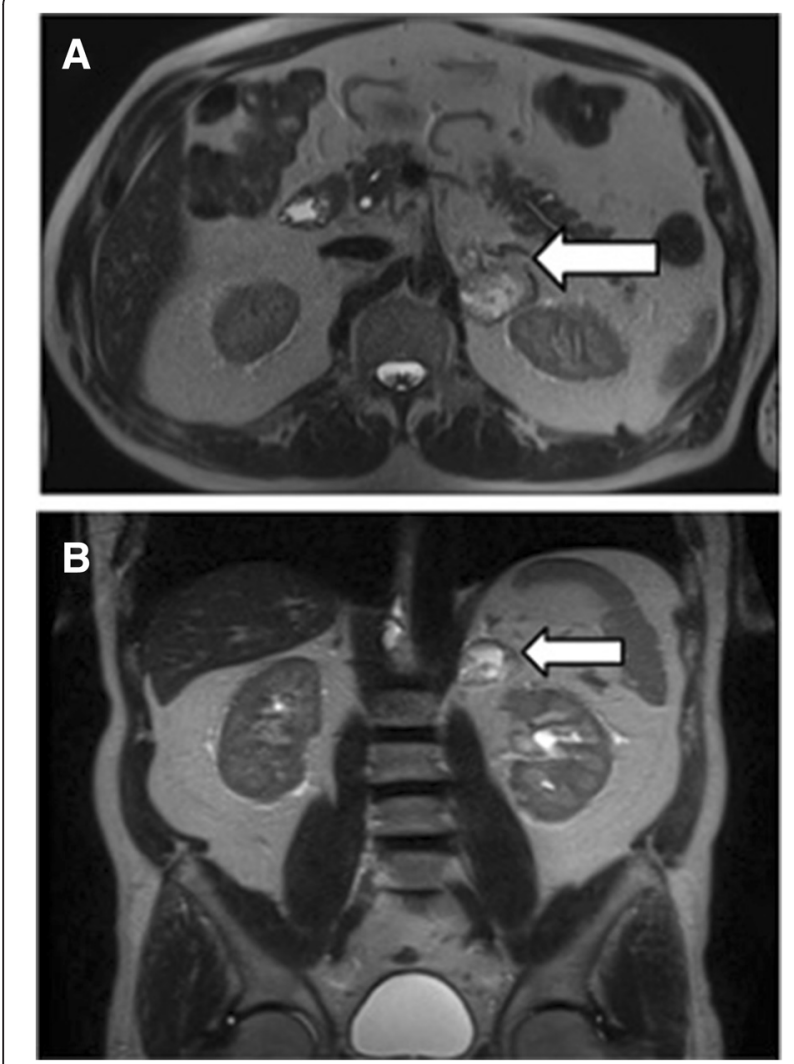

Fig. 1 Abdominal MRI scan. a Coronal MRI scan of the abdomen. b Axial MRI scan of the abdomen. The arrows indicate the surrenal mass: the signal was highly inhomogeneous and the central area was partially fluid
The surgical sample sent for pathological examination was composed of the adrenal gland and of a nodular mass of $4.5 \mathrm{~cm}$ in its greater diameter, with a hemorrhagic and partially necrotic cut surface. The histopathological report described an encapsulated proliferation, which consisted of atypical ganglion cells, in many of which neuro-melaninic pigment was evident, interspersed in a fibrillary matrix (Fig. 2a). In addition, a nodular proliferation of poorly differentiated spindle cells with a high mitotic index $(27 \mathrm{mi}-$ tosis per HPF, $\times 400$ ) and areas of necrosis was observed (Fig. 2b, c). The neoplastic cells were partially immunoreactive for synaptophysin and neurofilament, while they were negative for S100, Melanin A, CD99, CD31, CD34, podoplanin, cytokeratin AE1/ AE3, alpha-inhibin, and actin. These findings were consistent with a nodular ganglioneuroblastoma.

As guidelines suggest, the patient underwent total body CT scan and mIBG scintigraphy after the surgery and both were negative. The patients will continue follow-up schedule every 3 months.

\section{Discussion}

Neuroblastic tumors arise from sympathetic nervous system and are divided into three major categories according to Shimada et al. [2]: neuroblastoma, ganglioneuroblastoma, and ganglioneuroma. Ganglioneuroblastoma is a composite tumor containing both primitive neuroblasts and mature ganglion cells. It is a malignant tumor but less aggressive than neuroblastoma.
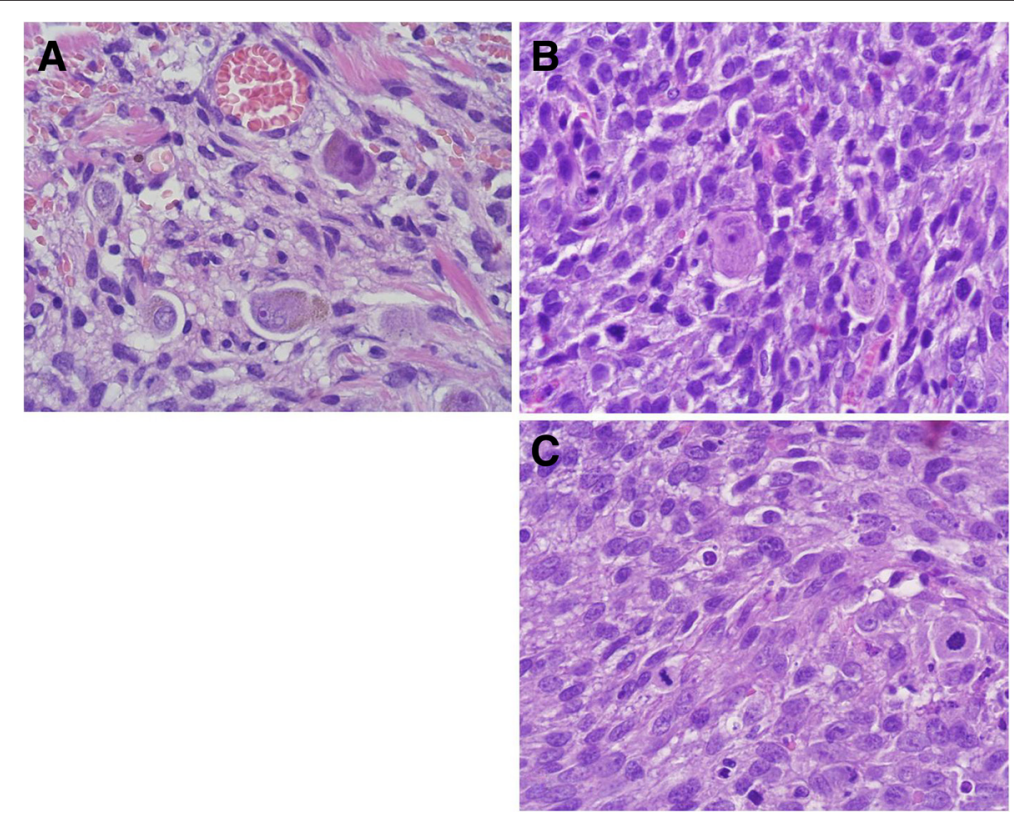

Fig. 2 The histopathological examination of the tumor showed a proliferation of atypical ganglion cells, in many of which neuro-melaninic pigment was evident, interspersed in a fibrillary matrix (a). A nodular proliferation of poorly differentiated spindle cells (b) with a high mitotic index (27 mitosis per HPF, ×400) (c) was also observed 
Table 1 International Neuroblastoma Pathology Classification

\begin{tabular}{|c|c|}
\hline Category and subtype & Pathology classification \\
\hline $\begin{array}{l}\text { Neuroblastoma } \\
\text { (Schwannian } \\
\text { stroma-poor) }\end{array}$ & \multirow{4}{*}{$\begin{array}{l}\text { FH and UH subgroups, based } \\
\text { on the combination of age, } \\
\text { grade of neuroblastic } \\
\text { differentiation, and MKI }\end{array}$} \\
\hline Undifferentiated & \\
\hline Poorly differentiated & \\
\hline Differentiating & \\
\hline $\begin{array}{l}\text { Ganglioneuroblastoma, } \\
\text { intermixed (Schwannian } \\
\text { stroma-rich) }\end{array}$ & $\mathrm{FH}$ \\
\hline $\begin{array}{l}\text { Ganglioneuroma } \\
\text { (Schwannian stroma- } \\
\text { dominant) FH }\end{array}$ & $\mathrm{FH}$ \\
\hline \multicolumn{2}{|l|}{ Maturing } \\
\hline \multicolumn{2}{|l|}{ Mature } \\
\hline $\begin{array}{l}\text { Ganglioneuroblastoma, } \\
\text { nodular (Schwannian } \\
\text { stroma-rich/stroma- } \\
\text { dominant and stroma- } \\
\text { poor) }\end{array}$ & $\mathrm{UH}^{\mathrm{a}}$ \\
\hline
\end{tabular}

FH favorable histology, UH unfavorable histology, MKI

mitosis-karyorrhexis index

${ }^{\text {a } T u m o r s ~ i n ~ t h i s ~ c a t e g o r y ~ w e r e ~ c l a s s i f i e d ~ i n t o ~ a n ~ u n f a v o r a b l e ~ h i s t o l o g y ~ g r o u p ~}$

according to the International Neuroblastoma Pathology Classification

The International Neuroblastoma Pathology Classification (INPC), established in 1999 and revised in 2003, redefined the histological features and proposed 4 tumor categories: NB (neuroblastoma), GNB-intermixed, GN (ganglioneuroma), GNB-nodular (classical). The four categories are divided in two distinct prognostic groups: Favorable Histology $(\mathrm{FH})$ and Unfavorable Histology (UH) $[3,4]$ (see Table 1).

The tumor type of the current case was GBN-nodular (classical), unfavorable histology.

The International Classification INSS (revised in 1993) is currently used for the staging of the disease (see Table 2) [5]. Important prognostic factors are age at the diagnosis (children $<1$ year old have the most favorable prognosis), primary site of the tumor (retroperitoneum and adrenal gland tumors bear a worse prognosis than mediastinum lesions), histology and stage of disease according to INSS [6].

Moreover, it is important to consider biological factors, in particular amplification of N-MYC (which is amplified in $20-30 \%$ of neuroblastomas) and deletion of the short arm of chromosome 1 that are related to poor prognosis $[7,8]$.

Ganglioneuroblastoma is a pediatric tumor and adult onset is extremely rare. In the literature, less than 50 cases of adult patients are reported [9]; the most frequent site is the adrenal gland; other sites are the retroperitoneum, the brain, and the mediastinum. In the adrenal gland, only 17 cases of GNB of the adult are reported, including our patient (see Table 3)
Table 2 The International Neuroblastoma Staging System (INSS)

\begin{tabular}{ll}
$\begin{array}{l}\text { Stage/Prognostic } \\
\text { group }\end{array}$ & Description \\
\hline Stage 1 & $\begin{array}{l}\text { Localized tumor with complete gross excision, } \\
\text { with or without microscopic residual disease; } \\
\text { representative ipsilateral lymph nodes negative } \\
\text { for tumor microscopically (i.e., nodes attached } \\
\text { to and removed with the primary tumor may } \\
\text { be positive). }\end{array}$
\end{tabular}

Stage 2A Localized tumor with incomplete gross excision; representative ipsilateral non-adherent lymph nodes negative for tumor microscopically.

Stage $2 B$

Localized tumor with or without complete gross excision, with ipsilateral non-adherent lymph nodes positive for tumor. Enlarged contralateral lymph nodes must be negative microscopically

Stage 3

Unresectable unilateral tumor infiltrating across the midline, with or without regional lymph node involvement; or localized unilateral tumor with contralateral regional lymph node involvement; or midline tumor with bilateral extension by infiltration (unresectable) or by lymph node involvement. The midline is defined as the vertebral column. Tumors originating on one side and crossing the midline must infiltrate to or beyond the opposite side of the vertebral column.

Stage 4

Any primary tumor with dissemination to distant lymph nodes, bone, bone marrow, liver, skin, and/or other organs, except as defined for stage 45 .

Stage 4S Localized primary tumor, as defined for stage 1, $2 \mathrm{~A}$, or $2 \mathrm{~B}$, with dissemination limited to skin, liver, and/or bone marrow (by definition limited to infants younger than 12 months). Marrow involvement should be minimal (i.e., $<10 \%$ of total nucleated cells identified as malignant by bone biopsy or by bone marrow aspirate). More extensive bone marrow involvement would be considered stage 4 disease. The results of the mIBG scan, if performed, should be negative for disease in the bone marrow.

mIBG metaiodobenzylguanidine

[9-23]. Most of them (14/17) were male, from 20 to 67 years old. Six patients (35\%) showed distant metastasis or local recurrence; metastatic sites were bone or bone marrow in three cases (17\%), lymph node in two cases (11\%), and liver in two cases (11\%). All patients underwent surgery and two of them underwent also radiotherapy and chemotherapy.

Treatment guidelines were derived from pediatric experience. The therapeutic strategy includes surgery, radiotherapy, and chemotherapy. Patients with N-MYC amplification or deletion of the short arm of chromosome 1 have aggressive disease, regardless of age and stage of disease. If the tumor is considered radically resectable, surgery represents the treatment of choice. Because of the high possibility of infiltration of regional lymph nodes, local lymph node dissection is recommended [24, 25]. 
Table 3 Results

\begin{tabular}{|c|c|c|c|c|c|c|}
\hline First author (year) & Age(years) & Sex & Size $(\mathrm{cm})$ & Metastasis & Treatment & Survival \\
\hline Butz (1940) [10] & 25 & M & $(-)$ & Liver & $(-)$ & $(-)$ \\
\hline Cameron (1967) [11] & 58 & $\mathrm{~F}$ & $(-)$ & None & Surgery & 3.5 years alive \\
\hline Takahashi (1988) [12] & 21 & M & 8.8 & Lymph node & Surg rad, chemo & 8 months \\
\hline Koizumi (1992) [13] & 47 & $\mathrm{~F}$ & 9 & Bone marrow & $(-)$ & 3 months \\
\hline Kishikawa (1992) [14] & 29 & M & 11 & Bone & Surg & $(-)$ \\
\hline Higuchi (1993) [15] & 29 & M & 11 & Bone & Surg & 10 months, alive \\
\hline Hiroshige (1995) [9] & 35 & M & 10 & None & Surg & 24 months \\
\hline Mehta (1997) [16] & 22 & M & 9 & $(-)$ & Surg & $(-)$ \\
\hline Rousseau (1998) [17] & $(-)$ & $\mathrm{F}$ & $(-)$ & Liver & Surg rad, chemo & $(-)$ \\
\hline Fujiwara (2000) [18] & 25 & M & $(-)$ & None & Surg & 5 years \\
\hline Leavitt (2000) [19] & 67 & M & $(-)$ & None & Surg & $(-)$ \\
\hline Slapa (2002) [20] & 20 & $\mathrm{~F}$ & 18 & None & Surg & 12 months alive \\
\hline Koike (2003) [14] & 50 & M & 4.5 & $(-)$ & Surg & 30 months \\
\hline Gunlusoy (2004) [21] & 59 & M & 17 & Lymph node & Surg & $(-)$ \\
\hline Mizuno (2006) [22] & 53 & M & 11 & Spine & Surg & 30 months, alive \\
\hline Gupta (2007) [23] & 40 & M & $(-)$ & None & Surg & $(-)$ \\
\hline Present case (2014) & 63 & M & 5 & None & Surg & 6 months alive \\
\hline
\end{tabular}

(-) not available

If the tumor is considered unresectable (stage 3), a diagnostic biopsy should be performed and treatment options are radiotherapy or cytoreductive chemotherapy. Chemotherapy is the treatment of choice in metastatic disease (stage 4) [26].

Active drugs in pediatric population are cyclophosphamide vincristine, adriamycin, and combinations with platinum and etoposide [27]. In high-risk patients (stage 4 or any stage with N-MYC amplification), chemotherapy schedules with higher dose intensity are recommended. Topotecan [28] and temozolomide [29] have recently demonstrated a significant antitumor activity in patients with relapsed disease. In stage 4 , the role of radiation therapy is controversial.

Recurrence of disease occurs mostly in the first 2 years after surgery. Attention to the symptoms and careful physical examination are fundamental. The patient should be examined every 3 months in the first and second year, then every 6 months. Complete blood count, urinary catecholamine analysis, and imaging of the site of the primary tumor (ultrasound or RX scan) should be performed at every examination.

It is recommended to perform MIBG scintigraphy every 6 months during the first and second year [1].

Few data are available regarding treatment of adults affected by GBN. In fact, it is not clear if chemotherapy schedules of pediatric studies are suitable and effective for metastatic disease in adults. Prognosis of GBN of the adult also remains uncertain because of the poorness of long-term data.

\section{Conclusions}

Ganglioneuroblastoma is typically a pediatric disease. Few cases of GBN of the adult are described from the literature. Surgery is the treatment of choice in stage 1 and 2 (children and adult), radiotherapy as a role in stage 3 disease, and chemotherapy is reserved for metastatic disease. Few data are available regarding the efficacy of chemotherapy in stage 4 in the adults. Because of the rarity of the pathology, all cases should be included in the rare cancer network.

\section{Consent}

Written informed consent was obtained from the patient for publication of this case report and any accompanying images. A copy of the written consent is available for review by the Editor-in-Chief of this journal.

\section{Abbreviations \\ GBN: ganglioneuroblastoma.}

\section{Competing interests}

The authors declare that they have no competing interests.

\section{Authors' contributions}

$\mathrm{EB}$ and BM drafted the manuscript. GP revised the manuscript critically. All authors read and approved the final manuscript.

\section{Acknowledgements}

The authors would like to express their gratitude to Dr. Silvia Uccella and Prof. Fausto Sessa for their important contribution to the manuscript and for providing histological images.

Received: 17 February 2015 Accepted: 3 July 2015

Published online: 11 September 2015 


\section{References}

1. Caron HN, Pearson ADJ. Neuroblastoma. In: Voute PA, Barrett A, Stevens MCG, Caron HN, editors. Cancer in children. 5th ed. Oxford: Oxford University Press; 2005. p. 337-52.

2. Shimada H, Chatten J, Newton Jr WA, Sachs N, Hamoudi AB, Chiba T, et al. Histopathologic prognostic factors in neuroblastic tumors: definition of subtypes of ganglioneuroblastoma and an age-linked classification of neuroblastomas. J Natl Cancer Inst. 1984;73:405-16.

3. Shimada H(1), Ambros IM, Dehner LP, Hata J, Joshi W, Roald B, et al. The international neuroblastoma pathology classification (the Shimada system) Cancer. 1999;86(2):364-72.

4. Peuchmaur $M$, d'Amore ES, Joshi W, Hata J, Roald B, Dehner LP, et al. Revision of the International Neuroblastoma Pathology Classification: confirmation of favorable and unfavorable prognostic subsets in ganglioneuroblastoma, nodular. Cancer. 2003;98(10):2274-81.

5. Brodeur GM, Pritchard J, Berthold F, Carlsen NL, Castel V, Castelberry RP, et al. Revisions of the international criteria for neuroblastoma diagnosis, staging, and response to treatment. J Clin Oncol. 1993;11(8):1466-77. Review.

6. Cotterill SJ, Pearson AD, Pritchard J, Foot AB, Roald B, Kohler JA, et al. Clinical prognostic factors in 1277 patients with neuroblastoma: results of The European Neuroblastoma Study Group 'Survey' 1982-1992. Eur J Cancer. 2000;36(7):901-8.

7. Bagatell R, Beck-Popovic M, London WB, Zhang Y, Pearson AD, Matthay KK et al. Significance of MYCN amplification in international neuroblastoma staging system stage 1 and 2 neuroblastoma: a report from the International Neuroblastoma Risk Group database. J Clin Oncol. 2009;27(3):365-70.

8. Spitz R, Hero B, Simon T, Berthold F. Loss in chromosome 11q identifies tumors with increased risk for metastatic relapses in localized and 45 neuroblastoma. Clin Cancer Res. 2006;12(11 Pt 1):3368-73.

9. Hiroshige K, Sonoda S, Fujita M, Takasugi M, Kuroiwa A, Inatomi H. Primary adrenal ganglioneuroblastoma in an adult. Intern Med. 1995;34(12):1168-73.

10. Butz H. Uber die sympathicoblastome des nebennierenmarkes. Virchows Arch. 1940;306:360-71.

11. Cameron DG, Warner HA, Szabo AJ. Chronic diarrhea in an adult with hypokalemic nephropathy and osteomalacia due to a functioning ganglioneuroblastoma. Trans Am Clin Climatol Assoc. 1967;78:205-17.

12. Takahashi Y, Kuriyama M, Komeda H, Horie M, Isogai K. Multimodality treatment of adrenal ganglioneuroblastoma: a case report. Acta Urol Jpn. 1988:34:2149-54

13. Koizumi T, Kanbayashi T, Ichiyoshi T, Nakamura M, Moriyama S. Ganglioneuroblastoma with disseminated bone marrow infiltration in an adult. Int Med J. 1992;31:1322-4.

14. Koike K, lihara M, Kanbe M, Omi Y, Aiba M, Obara T. Adult-type ganglioneuroblastoma in the adrenal gland treated by a laparoscopic resection: report of a case. Surg Today. 2003;33:785-90.

15. Higuchi M, Teshima T, Okada K. Autologous blood stem cells transplantation in an adult with ganglioneuroblastoma. Nippon Gan Chiryo Gakkai ShiJ. 1993;28:1135.

16. Mehta N, Tripathi RP, Popli MB, Nijhawan VS. Bilateral intraabdominal ganglioneuroblastoma in an adult. Br J Radiol. 1997;70:96-8.

17. Rousseau P(1), Bernard A, Favre JP, Arnould L, Cheynel N, Manuelian M. Ganglioneuroblastoma in the adult. Presse Med. 1998;27(33):1677-9.

18. Fujiwara T, Kawamura M, Sasou S, Hiramori K. Results of surgery for a compound adrenal tumor consisting of pheochromocytoma and ganglioneuroblastoma in an adult: 5-year follow-up. Intern Med. 2000;39(1):58-62.

19. Leavitt JR(1), Harold DL, Robinson RB. Adrenal ganglioneuroma: a familia case. Urology. 2000;56(3):508.

20. Slapa RZ, Jakubowski W, Kasperlik-Zaluska AA, Szopiñski K, Debski R, Samsel $\mathrm{M}$, et al. Adrenal ganglioneuroblastoma in pregnant woman: diagnosis with three-dimensional ultrasound. Eur Radiol. 2002;12:S121-6.

21. Gunlusoy B(1), Arslan M, Selek E, Sural S, Ayder AR. A case report: adrenal ganglioneuroblastoma in a 59-year old man. Int Urol Nephrol. 2004;36(4):481-3.

22. Mizuno S(1), lida T, Fujita S. Adult-onset adrenal ganglioneuroblastoma bone metastasis two years after surgery: report of a case. Surg Today. 2010;40(5):482-6.

23. Gupta R(1), Dinda AK. Ganglioneuroma of the adrenal gland: a rare case. Indian J Pathol Microbiol. 2007:50(4):782-4.
24. Adkins ES, Sawin R, Gerbing RB, London WB, Matthay KK, Haase GM. Efficacy of complete resection for high-risk neuroblastoma: a Children's Cancer Group study. J Pediatr Surg. 2004;39(6):931-6.

25. Murphy JM, La Quaglia MP. Advances in the surgical treatment of neuroblastoma: a review. Eur J Pediatr Surg. 2014;24(6):450-6.

26. Irwin MS, Park JR. Neuroblastoma: paradigm for precision medicine. Pediat Clin North Am. 2015;62(1):225-56. doi:10.1016/j.pcl.2014.09.015. Review.

27. Kohler JA, Rubie H, Castel V, Beiske K, Holmes K, Gambini C, et al. Treatment of children over the age of one year with unresectable localised neuroblastoma without MYCN amplification: results of the SIOPEN study. Eur J Cancer. 2013:49(17):3671-9.

28. Garaventa A, Luksch R, Biasotti S, Severi G, Pizzitola MR, Viscardi E, et al. A phase II study of topotecan with vincristine and doxorubicin in children with recurrent/refractory neuroblastoma. Cancer. 2003:98:2488-94.

29. Rubie H, Chisholm J, Defachelles AS, Morland B, Munzer C, ValteauCouanet $D$, et al. Phase II study of temozolomide in relapsed or refractory high-risk neuroblastoma: a joint Societe Francaise des Cancers de l'Enfant and United Kingdom Children Cancer Study Group-New Agents Group Study. J Clin Oncol. 2006;24:5259-64.

\section{Submit your manuscript to a SpringerOpen ${ }^{\circ}$ journal and benefit from:}

- Convenient online submission

- Rigorous peer review

- Immediate publication on acceptance

- Open access: articles freely available online

- High visibility within the field

- Retaining the copyright to your article

Submit your next manuscript at $>$ springeropen.com 